\title{
A EXPERIÊNCIA DE MULHERES NO PÓS-PARTO SOBRE O PLANEJAMENTO FAMILIAR
}

\section{Karla Samara da Silva Santos}

Graduada em Enfermagem pela Universidade do Estado da Bahia (UNEB), Brasil.

\section{Gilvânia Patrícia do Nascimento Paixão}

Doutora em Enfermagem. Docente da Universidade do Estado da Bahia (UNEB), Brasil.

\section{Priscilla Mecia Conceição de Brito}

Mestre em Saúde Coletiva. Docente da Universidade do Estado da Bahia (UNEB), Brasil.

\section{Aline Silva Jerônimo}

Mestre em Ciências da Saúde. Docente da Faculdade Estácio de Juazeiro (BA), Brasil.

\section{Ellen Hilda Souza de A. Oliveira}

Mestre em Saúde da Mulher. Docente da Universidade do Estado da Bahia (UNEB), Brasil.
RESUMO: O estudo objetivou analisar a experiência de mulheres no pós-parto, sobre o planejamento familiar. Neste período, a mulher tende a receber menor atenção dos profissionais de saúde, uma vez que os olhares estão mais voltados ao recém-nascido, e as questões relacionadas à sexualidade não recebem atenção. Pesquisa qualitativa, descritivo-exploratória, realizada com 17 mulheres no período de até um ano pós-parto. Foi utilizada a técnica da entrevista semiestruturada para a coleta de dados e a análise temática de Bardin para a sua organização. Após a análise do material verbal coletado, três categorias emergiram: Gravidez não planejada pela 'falha' do método; Consulta puerperal; e Planejamento familiar após o parto. O planejamento familiar preconizado pelo Ministério da Saúde não é compatível com as ações realizadas pela Estratégia de Saúde da Família (ESF). Isso porque as mulheres entrevistadas experienciaram, em sua maioria, gravidez indesejada e continuam vulneráveis a adquirir outras futuras gestações.

PALAVRAS-CHAVE: Gravidez não Desejada; Período Pós-Parto; Planejamento Familiar.

\section{EXPERIENCE OF POST-PARTUM FEMALES ON FAMILY PLANNING}

\begin{abstract}
Current research analyzed the experience of post-partum females on family planning. During this period, females tend to receive less attention by health professionals since the newly born baby comes foremost and sexual issues are not focused. Current qualitative, descriptive and exploratory research was undertaken with 17 females during a period of up to one year after birth. The half-structured interview was prepared for data collection and Bardin's thematic analysis for organization. After analyzing the verbal material, three categories emerged: non planned pregnancy due to the method's failure; puerperal attendance, family planning after child birth. Family planning as conceived by the Ministry of Health is not compatible with activities by the Family Health Strategy due to the fact that most interviewed females had undesired pregnancy and remained vulnerable to other future ones.
\end{abstract}

KEY WORDS: Non desired pregnancy; Post-partum period; Family planning.

\section{INTRODUÇÃO}

A sociedade, ao longo dos anos, vem sofrendo modificações culturais que têm colaborado para a captação de novos pensamentos e atitudes com relação à sexualidade. Tais mudanças têm influenciado 
no comportamento de pessoas que, atualmente, iniciam sua atividade sexual mais cedo. Junto com a precoce iniciação sexual, surge a necessidade de utilizar métodos contraceptivos que previnam uma gestação indesejada ${ }^{1}$.

Planejamento familiar é entendido como o conjunto de ações de regulação da fecundidade que garanta direitos iguais de constituição, limitação ou aumento da prole pela mulher, pelo homem ou pelo casal, orientandose por ações educativas e preventivas e pela garantia de acesso igualitário a informações, meios, métodos e técnicas disponíveis para a regulação da fecundidade. Com essa seguridade, os indivíduos podem espaçar e limitar as gestações de acordo com o desejo de ter ou não um filho, com impacto direto em sua saúde biopsicosocial e bem-estar, proporcionando-lhes total autonomia para a tomada de qualquer decisão ${ }^{2}$.

Para alcançar esta finalidade, segundo dados do Ministério da Saúde, são disponibilizados gratuitamente pelo Sistema Único de Saúde (SUS) oito tipos de métodos contraceptivos reversíveis, a saber: os preservativos feminino e masculino (camisinha), a pílula oral, a minipílula, a injetável mensal, a injetável trimestral, o dispositivo intrauterino (DIU), a pílula anticoncepcional de emergência e o diafragma. Há ainda a laqueadura de tubas uterinas para a mulher, e a vasectomia, para homens, procedimentos estes definitivos, e realizados através de intervenções cirúrgicas ${ }^{3}$.

As ações de planejamento familiar no Brasil, tratando-se de SUS, são desenvolvidas principalmente pela Estratégia Saúde da Família (ESF), cujas equipes multiprofissionais trabalham com população adscrita visando formação de vínculo entre o serviço e a comunidade ${ }^{4}$. Planejar um filho é de suma importância, visto que quando a gravidez ocorre em um momento não oportuno, há associação com fatores sociais, mortalidade e morbidade da mãe e da criança, especialmente em países de baixa renda ${ }^{5}$.

Ressalta-se que o intervalo entre gravidezes inferior a um ano é um fator de risco para parto prematuro e morte neonatal. No entanto, em situações de baixa ren$\mathrm{da}$, as gravidezes não intencionais geralmente ocorrem durante os primeiros 12 meses pós-parto-6. Para superar isso, o planejamento familiar pós-parto deve focar na prevenção da gravidez indesejada antes dos primeiros 12 meses após o parto, sendo perceptível o benefício de sua implementação para a sobrevivência materno-infantil. Evidências mostram que este planejamento pode impedir mais de $30 \%$ das mortes maternas e $10 \%$ da mortalidade infantil ${ }^{7}$.

No que tange à escolha do método contraceptivo, deve ser personalizada, levando-se em conta fatores como idade, números de filhos, compreensão e tolerância ao método, desejo de procriação futura e a presença de doenças crônicas que possam agravar-se com seu uso. Como todos os métodos têm suas limitações, é importante saber quais são elas, para que eventualmente possase optar por um dos mesmos. Todavia, na orientação sobre os métodos anticoncepcionais deve ser destacada a necessidade da dupla proteção (contracepção e prevenção às DST e HIV/AIDS), mostrando a importância dos métodos de barreira, como os preservativos masculinos ou femininos ${ }^{1}$.

Um dos grandes entraves ocorre pelo fato de que os programas nacionais de planejamento familiar de muitos países em desenvolvimento negligenciam as necessidades das mulheres que tiveram filho recentemente (puérperas). Dados de pesquisa realizada em 17 países, entre 2003 e 2007, relativos ao uso de anticoncepcionais, demonstraram taxas de necessidades não atendidas que variam de $50 \%$ em Bangladesh para $88 \%$ no Mali. Nesta amostra, as mulheres provavelmente atrasariam a adoção de contracepção até os nove meses após o parto, tornando-as mais propensas a ter uma necessidade insatisfeita de planejamento familiar do que as outras mulheres em geral ${ }^{8}$.

São escassos ainda, no Brasil, estudos referentes à satisfação de mulheres sobre planejamento familiar no pós-parto, não sendo possível encontrar dados de pesquisas referentes ao uso de métodos contraceptivos durante esse período, tornando o assunto ainda mais relevante, instigando para um olhar mais amplo em relação à assistência integral que deve ser prestada à mulher no período pós-parto.

Diante desses elementos, a seguinte questão de pesquisa surgiu: Quais as experiências de mulheres no pós-parto sobre o planejamento familiar? Para responder o questionamento, vislumbrou-se um estudo que pudesse investigar o tema, a partir da fala das mulheres. Assim, 
fora delineado o seguinte objetivo geral: Analisar a experiência de mulheres no pós-parto, sobre o planejamento familiar.

\section{METODOLOGIA}

Trata-se de um estudo descritivo-exploratório, com abordagem qualitativa. Dentre as pesquisas descritivas salientam-se aquelas que têm por objetivo descrever sentimentos, opiniões, trazer características individuais, conhecer os aspectos da vida social, comportamentos e atitudes do grupo a ser estudado, o que números ou estatísticas não conseguiriam alcançar, devido à complexidade do fenômeno, como é o caso deste estudo?.

A pesquisa foi desenvolvida em duas Estratégias de Saúde da Família (ESF), pertencentes ao município de Senhor do Bonfim (BA), tendo como colaboradoras 17 mulheres cadastradas nas respectivas unidades. A aproximação com as participantes se deu através dos Agentes Comunitários de Saúde (ACS), e pela busca ativa nas salas de vacinas ou em salas de espera. Os critérios de inclusão foram mulheres que tiveram filhos até, no máximo, um ano, excluindo-se assim aquelas que não estivessem dentro do estabelecido.

Os dados foram coletados a partir de entrevistas semiestruturadas, combinando perguntas abertas e fechadas, sobre aspectos das características sociodemográficas, informações obstétricas, histórico de acompanhamento da última gestação, rotina após o parto e perguntas norteadoras ligadas ao objeto do estudo. Os locais das entrevistas foram nas residências das mulheres (acompanhada do ACS), ou em uma sala reservada na Unidade de Saúde. Durante a coleta foi utilizado um gravador de voz, para que informações não se perdessem, e após realizada a transcrição. A saturação de dados foi o principal fator para estabelecer o número final de colaboradoras.

Após realizar a transcrição, o material foi analisado utilizando o método de análise de conteúdo de Bardin, visando obter indicadores que permitissem a inferência de conhecimentos relativos às condições de produção/recepção destas mensagens, buscando compreender as características, estruturas ou modelos que estão por trás dos fragmentos de mensagens considerados ${ }^{10}$.
Para respeitar os aspectos éticos expostos na Resolução 466/12, que norteia as pesquisas com seres humanos, a pesquisadora considerou o respeito pela dignidade humana e pela especial proteção aos participantes do estudo. Desse modo, a pesquisa foi realizada reconhecendo os valores e direitos, levando em conta os princípios da bioética como não maleficência, beneficência, justiça, autonomia e equidade, com o intuito de preservar a dignidade humana. As entrevistadas foram esclarecidas sobre a preservação dos dados e identidade, a gratuidade da participação, bem como que a desistência poderia acontecer a qualquer momento.

Todos esses aspectos foram explicitados no Termo de Consentimento Livre e Esclarecidos (TCLE) das participantes, contendo todas as informações necessárias, em linguagem clara e objetiva, de fácil entendimento, para o mais completo esclarecimento. O referido termo foi assinado pelas mulheres e pesquisadoras. A aprovação pelo Comitê de Ética em Pesquisa (CEP) ocorreu no mês de junho de 2017, através do CAAE 68189317.0.0000.0057 e parecer número 2.102.383, e a coleta de dados iniciada no mês de agosto do mesmo ano.

\section{RESULTADOS}

As participantes pertencem à faixa etária de 17-36 anos, e se caracterizaram por ser em sua maioria parda (n $=14)$, com ensino médio $(\mathrm{n}=9)$, renda de até um salário mínimo $(\mathrm{n}=9)$, e religião católica $(\mathrm{n}=7)$. Após a análise do material verbal coletado, três categorias e sete subcategorias emergiram, estando dispostas a seguir:

\section{GRAVIDEZ NÃO PLANEJADA PELA 'FALHA' DO MÉTODO}

As participantes do estudo relatam que estavam fazendo uso de algum tipo de contraceptivo, na ocorrência da gravidez. As falas abaixo mostram que algumas engravidaram enquanto usavam um método que já era de costume, enquanto para outras a concepção ocorreu na troca do método. 
Tomava o ciclo 21 [comprimido - 21 drágeas] há, aproximadamente, seis anos e dai engravidei. (M8)

Utilizava a algestona mensal e engravidei tomando essa injeção. (M9)

Utilizava a camisinha, desde a minha primeira gravidez. (M11)

Eu tomava comprimidos e na troca para a injeção eu engravidei. (M14) Usava desde que tive minha filha, há 5 anos. Eu comecei com o triquilar [comprimido - 21 drágeas], que pegava no posto. Depois não veio mais e passei a pegar o ciclo 21 porque me disseram que continha as mesmas substâncias. Com 30 dias acabei engravidando. (M17)

\section{CONSULTA PUERPERAL}

\section{Não Retornou à Unidade para a Consulta}

Nesta categoria, algumas depoentes referem que não retornaram após o parto, para consulta puerperal ou subsequente. Nas falas é possível ver que as mulheres não dão importância e/ou desconhecem a necessidade desse atendimento, que é por vezes esquecido em detrimento dos cuidados com o recém-nato.

Como foi cesárea fiquei os três meses [em repouso], quando retornei não deu certo [a consulta] e até agora não fui ainda, quando fui [novamente] não fui atendida, $e$ pediram para remarcar. (M9)

Até agora não [foi à consulta], mas a Agente Comunitária de Saúde mandou eu ir lá [na ESF] (M8).

Ainda não [foi à consulta]. Fiz todos os exames do bebê, já passei duas vezes [na puericultura] e ainda não falaram sobre anticoncepcional.

\section{Retornou para Consulta Puerperal}

Outras mulheres relataram que retornaram para atendimento após o parto. Quando questionadas a respeito do teor da consulta, a inserção dos métodos contraceptivos foi a única assistência prestada, como elucidado nas falas a seguir:
Ela [médica] me orientou que, mesmo ligando [fez laqueadura tubária], devo usar o método [anticoncepcional] durante as relações sexuais. Falou também que não era garantido [a laqueadura], porque muitas mulheres que ligaram podem engravidar. Mas quando foi pra me ligar, pedi ao médico pra mostrar tudo e ele me mostrou. Ele disse que só Deus pra regenerar as trompas, porque eu não engravidava mais. (M2) Eu só voltei nela [enfermeira] porque menstruei duas vezes em um mês. Ela falou que era normal e perguntou se eu queria a de três meses [injetável trimestral], mas eu preferia a mensal. (M5)

Ele [médico] só passou um anticoncepcional e pediu pra eu voltar com seis meses. (M11)

Só passou o anticoncepcional e o preservativo. Não deu orientações, porque eu e a bebê passamos juntas [na consulta]. (M12)

Nem olhou pra minha cara praticamente. (M13)

A ginecologista passou a injeção de três meses e a enfermeira explicou que quando começar a tomar a injeção devo usar preservativo durante os primeiros 15 dias, nas relações [sexuais]. (M17)

\section{Planejamento familiar após o parto}

\section{SOBRE FUTURAS GRAVIDEZES}

As depoentes relatam perspectivas variadas como: desejo de ter outro filho; realizar a laqueadura, para cessar definitivamente as possibilidades de uma gravidez. Salienta-se que muitas mulheres atribuem o fato de não desejar outro filho por conta das condições financeiras não satisfatórias e/ou de passar novamente por complicações no parto.

Quero outro sim, porque só liga se tiver mais outro filbo. Eu não vou ficar a vida toda tomando remédio. (M5)

O pai e eu queríamos uma mulherzinha. Veio aqui [menino] e a gente tá agradecendo a Deus porque veio com saúde. Quero tentar novamente. (M8) 
As condições estão difíceis de ter mais filhos, nem esse [filho] eu queria. Aconteceu, tem que cuidar. (M9) Por enquanto não quero mais. É muito bom, mas ao mesmo tempo é muito trabalho porque tem que ralar muito para sustentar a vida de um filho. (M10)

Nessa gravidez tive pré-eclâmpsia e não quero mais filbo. (M17)

\section{MÉTODO CONTRACEPTIVO UTILIZADO}

Pelas falas, pode-se perceber que as entrevistadas utilizam alguma forma de evitar a gravidez, seja pela abstinência sexual ou pelo uso de preservativos ou anticoncepcionais.

Desde o primeiro mês [pós-parto] estou tomando remédio por conta própria e me cuidando. (M1) Não tenho tido relação sexual. (M6) $\mathrm{O}$ médico disse que me ligou. Até hoje eu não fiz exames pra comprovar se ele fez ou não [a laqueadura], mas eu acho que sim, ou eu já tinha tido outro [filho]. (M9)

Depois que ela [filha] nasceu, fiquei dois meses sem relação sexual agora tenho usado preservativo. (M11) Até agora só estou usando a camisinha. Disseram que quem está amamentando não pode tomar a injeção, então comecei a usar [0 preservativo] desde os três meses [após o parto] porque eu estava com medo. (M15)

\section{COMO É REALIZADO O USO DO MÉTODO}

Nesta categoria pode-se perceber que existe um uso errôneo da medicação contraceptiva, quando esta se apresenta em forma de comprimidos com necessidade de intervalo, como é o caso das pílulas orais combinadas.

Toda noite eu tomo um [comprimido do ciclo 21] e quando a menstruação está para descer eu paro de tomar e só volto quando suspende. (M10)

Quando a medicação é sem intervalos (minipílulas), ou já tem as datas certas de retornar para uma nova administração (injetável), o uso do método é realizado da forma correta.

Tomo à noite todos os dias [comprimidos minipílula], sempre seguindo a seção dos dias. (M13)

Como eu tomei essa semana [injetável trimestral], só vou tomar daqui a três meses. (M16)

Em relação ao método de barreira, a responsabilidade sobre o uso do preservativo é outorgado ao companheiro, e a mulher se exime dessa função.

No caso, meu esposo que usa [preservativo masculino]. (M11)

\section{ACEITAÇÃO DO CASAL}

De uma maneira geral, houve concordância sobre o uso do método pelo casal, ainda que uma resistência masculina seja notada quanto ao uso do preservativo.

Eu gosto, porque se fosse por ele [anticoncepcional oral] eu não teria engravidado. Já a injeção [prescrita pela ginecologista] eu não gostei porque não me fazia bem. Eu sentia muito enjoo e dor de estômago. Ele gostou [parceiro] também achou melhor porque não estamos tendo condições de ter outro filbo. (M14) Achamos [casal] bom, seguro e melhor [preservativo masculino]. (M7) Gosto de usar [preservativo masculino] porque eu não me sinto bem usando remédio, então é a única forma que a gente viu. Não pude ligar por conta que meu útero estava muito fino. Ele [parceiro] não tem nada contra. (M11)

\section{AUTONOMIA FEMININA EM RELAÇÃO AO USO DO MÉTODO}

Nos casos em que o método escolhido é o preservativo, algumas mulheres relatam a resistência do companheiro. Apesar disso, as participantes revelam que têm autonomia em decidir pelo uso. 
Eu acho bom, mas por ele [parceiro] não usava o preservativo. (M9) As pessoas dizem que faz diferença [preservativo masculino], mas eu não achei diferença nenhuma. Ele [parceiro] não gosta, mas é obrigado. (M15)

\section{DISCUSSÃO}

De acordo com a primeira categoria, sobre gravidez não planejada pela 'falha' do método, os dados revelaram que a experiência de mulheres com o planejamento familiar perpassa por diversas questóes. Foi recorrente a declaração de gravidez indesejada, mesmo com o uso de algum método contraceptivo de costume, ou em sua troca, o que infere ao erro no manejo da medicação, seja pela falta de informação ou má interpretação e entendimento desta. Sabe-se que mundialmente a maioria das gestações, principalmente pós-parto, não são planejadas, sendo baixo o nível de conhecimento, especialmente em ambientes de baixa renda $a^{5-8}$. Justifica-se pela falta de informações e dificuldade de acesso a esses métodos, do uso inadequado dos mesmos, descontinuidade na oferta do contraceptivo pelo serviço, oferta limitada na variedade dos métodos e efeitos colaterais adversos que levam ao abandono e ao limite de eficácia, havendo uma contradição entre as proposições das políticas públicas de saúde e a prática desenvolvida na ESF ${ }^{11}$.

Com relação à segunda categoria, sobre consulta puerperal, essa situação se agrava pelo fato de que, após o parto, a maior parte das entrevistadas não retornou à consulta puerperal, desconhecendo a necessidade desse atendimento, que é por vezes subjugado em detrimento dos cuidados com o recém-nato. Por esse motivo, embora dados de 27 países em desenvolvimento mostrem que 95\% das mulheres após o parto querem evitar uma gravidez por, pelo menos, dois anos, na maioria dos casos, a atividade sexual é retomada antes da primeira menstruação pós-parto sem o uso de qualquer método anticoncepcional ${ }^{7}$.

Ainda quando um método é escolhido, muitas vezes os casais têm dificuldade em usá-lo de forma correta ou consistente, resultando em gravidezes indesejadas ${ }^{8}$.
Nessa perspectiva, autores reforçam que informação adequada em planejamento familiar é de fundamental importância, impedindo mais de 30\% das mortes maternas e $10 \%$ da mortalidade infantil 7 . Isso porque possibilita ao cliente exercer seus direitos, reconhecer métodos contraceptivos e fazer escolhas com autonomia ${ }^{12-13}$.

Outra faceta presente nos achados desse estudo, de acordo com a terceira categoria sobre planejamento familiar após o parto, refere-se a mulheres que relataram o retorno à Unidade de Saúde no período puerperal. É importante salientar que a busca pelo serviço se deu por motivos outros como a desregulação no ciclo menstrual e/ou para consulta do recém-nascido. Nessas situações os profissionais aproveitaram a oportunidade para prescrever uma medicação contraceptiva para a mulher. Dentre as medicações prescritas, a mais comum foi a injetável trimestral combinada ao método de barreira, disponíveis no Sistema Único de Saúde (SUS). No entanto, a prescrição foi realizada sem a devida instrução, tampouco com preocupação em buscar o histórico e/ ou saber sobre o desejo das pacientes, a fim de tentar adequar ao método preferível pelas mesmas.

De acordo com o Ministério da Saúde, em relatório de avaliação das Equipes de Saúde da Família, mais da metade dos profissionais médicos e enfermeiros, atuantes em saúde da mulher, não foram capacitados para as ações em planejamento familiar. Apenas 31,1\% das equipes tinham médicos que haviam recebido treinamento específico, percentual que alcançou 44,1\% para os enfermeiros, o que causa insegurança e descrença por parte dos usuários ${ }^{14}$.

Confirmando o ponto apresentado pelo MS, algumas mulheres no pós-parto que tiveram uma gravidez indesejada, apresentam insegurança sobre o uso do método contraceptivo prescrito. Muitas optam por abstinência sexual, cirurgia, ou outro método que diverge ao prescrito, levando ao uso das medicações de forma errada ou de automedicação, por acharem que um método, que já tiveram um contato prévio, é mais seguro e provoca menos efeitos adversos do que o atual prescrito. Pesquisadoras corroboram com a pesquisa, à medida que seu estudo revelou que mulheres fazem uso de métodos contraceptivos hormonais sem prescrição, pelo fácil acesso e baixo custo. Salientam ainda para a prática da auto- 
medicação no Brasil, que dentro dos indivíduos adultos supera a taxa dos $35 \%{ }^{15}$.

Nos achados deste estudo foi possível apreender ainda que as mulheres em uso de métodos contraceptivos orais, sem a devida orientação, estão mais propícias a adquirir uma gravidez indesejada, visto que as mesmas não têm noção de como utilizá-los de forma correta, apresentando dúvidas quanto ao intervalo entre as cartelas e a influência da menstruação. Esses dados podem ser confirmados por estudo realizado em um sistema municipal de saúde de Fortaleza (CE), com uma amostra de 264 mulheres, onde verificou-se que embora as participantes usassem métodos hormonais, faltava-lhes conhecimento sobre questões básicas. A incompreensão abarcou itens como: início correto do uso da cartela de AOC de baixa dose; regularidade no horário das tomadas da pílula; condutas a serem adotadas mediante o esquecimento de uma ou mais pílulas; intervalo entre cartelas; além de total desconhecimento sobre as complicações advindas de seu uso ${ }^{16}$.

Já as que estavam utilizando os métodos injetáveis obedeciam às datas de retorno, fazendo com que corressem menos riscos. Os métodos de barreira foram mais difíceis de serem analisados se são utilizados em todas as relações sexuais ou durante todo o ato, pelo fato de que muitas mulheres não souberam explicar e/ou sentiam-se envergonhadas em falar sobre esse assunto. Além disso, existe uma maior resistência quanto ao uso desse método pelo casal, principalmente pelo parceiro. Vale lembrar sempre que possível de envolver o homem no planejamento reprodutivo. Autores demostraram que a decisão sobre o uso dos métodos também está positivamente associada ao envolvimento do parceiro ${ }^{6-17}$.

Portanto, sabe-se que o aconselhamento contraceptivo no pós-parto, com enfoque nas intervenções educacionais, está associado a um aumento do uso de anticoncepcionais e melhores resultados do planejamento. Mesmo sendo simples, uma revisão de Inquéritos Demográficos e de Saúde de 17 países mostrou que quase dois terços das mulheres em seu primeiro ano de pós-parto têm uma necessidade insatisfeita de planejamento reprodutivo 5 .

Quando questionadas sobre futuras perspectivas, a maioria das entrevistadas salienta o fato de não dese- jar outros filhos, atribuindo essa decisão aos seguintes fatores: terem filhos suficiente; necessidade de muito cuidado; condições financeiras não satisfatórias; e/ou medo de passar por complicações na gestação e/ou parto. Para as que ainda querem uma gestação futuramente, há a esperança de vir um(a) filho(a) do sexo oposto aos filhos que já têm, ou justificam o desejo pela expectativa de realizar a laqueadura de tubas uterinas para cessar definitivamente as possibilidades de uma nova gestação e não mais utilizar métodos contraceptivos. Salienta-se que segundo o Art. 10, parágrafo $2^{\circ}$ da Lei $9.263 / 96$ "É vedada a esterilização cirúrgica em mulher durante períodos de parto ou aborto, exceto nos casos de comprovada necessidade, por cesarianas sucessivas anteriores" ${ }^{2}$.

\section{CONSIDERAÇÕES FINAIS}

Ao fim deste estudo, foi constatado que o planejamento familiar preconizado pelo Ministério da Saúde não é compatível com as ações realizadas pela ESF. Isso porque as mulheres entrevistadas experienciaram, em sua maioria, gravidezes indesejadas e continuam vulneráveis a adquirir outras futuras gestações, visto que continuam sem as devidas orientações, repercutindo no uso do método contraceptivo atual de forma errônea. Isso demonstra claramente a fragilidade que perpassa nas consultas de pré-natal e puerpério, associado aos problemas sociais aqui discutidos.

A importância principal deste estudo está em alertar os serviços públicos para as falhas que existem na atenção primária à saúde, em um contexto onde mesmo quando há uma boa assistência no pré-natal, o retorno da mulher para a consulta puerperal é marcado pela negligência e/ou não visibilidade dessa questão pelo profissional de saúde, o que perpassa principalmente pela falha em sua formação. Isso porque, usualmente, o profissional volta seus cuidados ao recém-nato, e não aproveita o momento oportuno para esclarecer dúvidas e efetivar o planejamento.

Sem brechas para dirimir suas dúvidas, muitas puérperas não retornam às consultas subsequentes, pois não foram informadas da necessidade, deixando, assim, as suas necessidades básicas em detrimento do filho. 
Como resultado, tem-se mulheres tomando decisões por conta própria, fazendo com que as mesmas utilizem medicações de forma incorreta e/ou automedicações, sem o conhecimento do risco que estão acometidas.

Este estudo limita-se pelas questões culturais e territoriais do lócus da pesquisa, como escolaridade, representação social, bem como conduta profissional. Infere-se que o mesmo estudo aplicado em outra realidade pode apresentar outros resultados, que não os aqui encontrados, uma vez que podemos em outro território encontrar por exemplo profissionais que sejam treinados para suprir essa necessidade puerperal.

\section{REFERÊNCIAS}

1. Almeida APF de, Assis MM de. Efeitos colaterais e alterações fisiológicas relacionadas ao uso contínuo de anticoncepcionais hormonais orais. Rev Eletrôn Atualiza Saúde. 2017; 5 (5): 85-93.

2. Brasil. Lei $\mathrm{n}^{0} 9.263$, de 12 de Janeiro de 1996. Regula o $\S 7^{\circ}$ do art. 226 da Constituição Federal, que trata do planejamento familiar, estabelece penalidades e dá outras providências. Diário Oficial da União. 12 jan. 1996.

3. Brasil, Departamento de Atenção Básica. Saúde Sexual e Saúde Reprodutiva. Cadernos de Atenção Básica. 2010.

4. Moura LNB de, Gomes KRO. Planejamento familiar: uso dos serviços de saúde por jovens com experiência de gravidez. Cien Saude Colet. 2014; 19 (3): 853863.

5. Ayiasi RM, Muhumuza C, Bukenya J, Orach CG. The effect of prenatal counselling on postpartum family planning use among early postpartum women in Masindi and Kiryandongo districts, Uganda. Pan Afr Med J. 2015; 21.

6. Brunson MR, Klein DA, Olsen CH, Weir LF, Roberts TA. Postpartum contraception: initiation and effectiveness in a large universal healthcare system. Am J Obstet Gynecol [Internet]. Elsevier Inc.; 2017; 217 (1): 55. e1-55.e9. Available from: http://dx.doi. org/10.1016/j.ajog.2017.02.036
7. Mengesha ZB, Worku AG, Feleke SA. Contraceptive adoption in the extended postpartum period is low in Northwest Ethiopia. BMC Pregnancy Childbirth [Internet]. BMC Pregnancy \& Childbirth; 2015; 15 (1): 1-6. Available from: http://dx.doi.org/10.1186/ s12884-015-0598-9

8. Pasha O, Goudar SS, Patel A, Garces A, Esamai F, Chomba E, et al. Postpartum contraceptive use and unmet need for family planning in five low-income countries. 2015; 12 (Suppl 2): 1-7.

9. Lakatos EM, Marconi M de A. Fundamentos de metodologia científica. Editora Atlas S. A. 2010.

10. Santos FM. Resenha análise de conteúdo: a visão de Laurence Bardin. Rev Eletrônica Educ [Internet]. 2012; 6 (1): 383-7.

11. De Coelho EAC, De Andrade MLS, Vitoriano LVT, De Souza JJ, Da Silva DO, Gusmão MEN, et al. Associação entre gravidez não planejada e o contexto socioeconômico de mulheres em área da Estratégia Saúde da Família. ACTA Paul Enferm. 2012.

12. Pierre LA dos S, Clapis MJ. Planejamento familiar em Unidade de Saúde da Família. Rev Latino-Am Enferm. 2010.

13. Silva RM da, Araújo KNC de, Bastos LAC, Moura ERF. Planejamento familiar: significado para mulheres em idade reprodutiva. Cien Saude Colet. 2011.

14. Brasil. Ministério da Saúde. Avaliação normativa do Programa Saúde da Família no Brasil: monitoramento da implantação e funcionamento das equipes de Saúde da Família - 2001/2002. C. Projetos, Programas e Relatórios. 2004.

15. Brandão ER, Cabral $C$ da $S$, Ventura M, Paiva SP, Bastos LL, Oliveira NVBV de, et al. "Bomba hormonal": os riscos da contracepção de emergência na perspectiva dos balconistas de farmácias no Rio de Janeiro, Brasil. Cad Saude Publica. 2016.

16. Americo CF, Nogueira PSF, Vieira RPR, Bezerra CG, Moura ERF, Lopes MV de O. Conhecimento de usuárias de anticoncepcional oral combinado de baixa dose sobre o método. Rev Lat Am Enfermagem. 2013.

17. Dourado I, MacCarthy S, Reddy M, Calazans G, Gruskin S. Revisiting the use of condoms in Brazil. Rev Bras Epidemiol [Internet]. 
2015;18 (suppl 1):63-88. Available from: http://

www.scielo.br/scielo.php?script $=$ sci_arttex-

t\&pid =S1415-790X2015000500063\&lng=en\&tl-

$\mathrm{ng}=\mathrm{em}$

Recebido em: 24/08/2018

Aceito em: 28/12/2018 